\title{
Evaluation of non-linear root water uptake model under different agro-climates
}

\author{
Arunava Poddar ${ }^{1}$, Navsal Kumar ${ }^{1}$, Rohitashw Kumar ${ }^{2, *}$, Vijay Shankar ${ }^{1}$ and \\ M. K. Jat ${ }^{3}$ \\ ${ }^{1}$ Civil Engineering Department, National Institute of Technology, Hamirpur 177 055, India \\ ${ }^{2}$ College of Agricultural Engineering and Technology, Sher-e-Kashmir University of Agricultural Sciences and Technology of Kashmir, \\ Srinagar 190 025, India \\ ${ }^{3}$ Civil Engineering Department, Malaviya National Institute of Technology, Jaipur (Raj), Jaipur 302 017, India
}

\begin{abstract}
The present study examines the effectiveness of a nonlinear root water uptake (RWU) model for different agro-climates. Evaluation of $\mathrm{O}-\mathrm{R}$ model is performed for three agro-climates considering secondary data of Roorkee (semi-arid), Solan (sub-temperate subhumid) and primary data of Hamirpur (humid subtropical region). Field experiments on maize (Zea mays), Indian mustard (Brassica Juncea) and wheat (Triticum aestivum) were conducted at different locations. The RWU model with a numerical simulation was developed for predicting moisture movement in the crop root zone. The predicted results were compared with the observed field data. Qualitative and quantitative evaluations were performed on the basis of soil moisture profile in the crop root zone, soil moisture depletion and soil moisture variation during crop period at different root zone depths. The modelpredicted and field-observed values were found to be in strong agreement for all the parameters indicating the efficacy of the numerical model coupled with nonlinear RWU model in predicting soil moisture dynamics in root zone.
\end{abstract}

Keywords: Crop root zone, crop evapotranspiration, lysimeter, numerical model, O-R model.

IN developing countries like India, where water availability is scarce, scientific approaches are necessary for effective utilization of the water resources. Irrigation sector alone accounts for more than $70 \%$ of water abstractions. Hence, it is imperative to conserve water and optimize crop yield through efficient irrigation ${ }^{1}$. This is generally achieved through development of optimal irrigation schedules which necessitate precise information on water requirements of crops. The crop water requirements are essentially governed by soil, crop and climatic variables under consideration ${ }^{2,3}$. Root uptake is a significant component of field water balance study. It has been observed that each crop possesses its own root water uptake (RWU) behaviour ${ }^{4}$.

*For correspondence. (e-mail: rohituhf@rediffmail.com)
Generally, RWU is described as a function of actual transpiration, soil moisture availability and vertical root distribution to the crops $^{5,6}$. Numerous RWU models based on different moisture movement pattern are available in literature of which the most prominent models are constant $^{7}$, linear $^{8}$, non-linear ${ }^{9}$ and exponential ${ }^{10,11}$. Numerical simulation of soil moisture dynamics considering RWU models has been widely reported in several studies ${ }^{4,12-21}$. Ojha et $a$. $^{22}$ carried out a comparative evaluation of different RWU models considering primary data (field experiments) and secondary data ${ }^{23}$. The results indicated that the non-linear model performed better than other RWU models in estimating moisture extraction by crops. Kumar et al. ${ }^{24}$ reviewed numerous RWU models and suggested that non-linear and exponential models provide better moisture extraction prediction efficiency.

The non-linear RWU model (hereinafter referred to as $\mathrm{O}-\mathrm{R}$ model) is an improvement over the linear RWU model by including a non-linearity coefficient. The nonlinearity coefficient accounts for the non-linear behaviour of RWU by crops ${ }^{9}$. Shankar et al. ${ }^{25}$ developed a method for computing the optimal value of non-linearity coefficient from crop physiological parameters, i.e. maximum daily transpiration, time and maximum root depth to attain the maximum transpiration value. The O-R model has been tested for uniform vis-à-vis multi-layered crop root zone and results indicated its efficacy for multilayer soils with varying soil properties for different depth ${ }^{25}$. Studies commented on the utility of O-R model under different agro-climates; however, only a handful attempts have been made in the past. The agro-climate of a region has considerable effect on crop water requirements and soil moisture dynamics, thereby governing the yield of the crops $^{26}$. Moreover, the description of agro-climate enables research effort to be more focused ${ }^{27}$. The present study is focused on evaluating the potential of O-R model under different agro-climates to establish its efficacy.

For present study, maize, wheat and Indian mustard are considered, since they are cultivated in a wide range of climates and are popular in hilly terrains as well ${ }^{14,28}$. The study considers three agro-climates which includes secondary data for two agro-climates (semi-arid and 
sub-temperate sub-humid) and primary data (humid subtropical) for the third one.

\section{Materials and methods}

\section{Numerical model}

The Richards (mixed form) equation ${ }^{29}$ representing vertical moisture (one-dimensional) flow in a cropped soil is written as ${ }^{30}$

$$
\frac{\partial}{\partial z}\left[k(\psi)\left(\frac{\partial \psi}{\partial z}\right)+1\right]+S(z, t)=\frac{\partial \theta}{\partial t}
$$

where $K$ (a function of $\psi$ ) is the hydraulic conductivity; $S$ $\left(z_{2} t\right)=$ sink term accounting moisture uptake; $\psi$ the pressure head; $\theta$ (a function of $\psi$ ) $=$ volumetric moisture content; $t$ the time and $z$ the vertical distance measured positive upward.

\section{Constitutive relationships}

$\theta-\psi$ relationship: Van Genuchten ${ }^{31}$ has given the constitutive relations between moisture content, pressure head and hydraulic conductivity

$$
\Theta=\left[\frac{1}{1+\left\|\alpha_{v} \psi\right\|^{n_{v}}}\right]^{m_{v}}
$$

$$
\text { For } \psi<0 \text {, for } \psi \geq 0=1 \text {, }
$$

where $\alpha_{v}$ and $n_{v}$ are unsaturated soil hydraulic parameters with $m_{v}=1-\left(1 / n_{v}\right)$ and $\Theta$ is the effective saturation computed as $\Theta=\theta-\theta_{r} / \theta_{s}-\theta_{r}$ where $\theta_{s}$ the saturated moisture content and $\theta_{r}$ the residual moisture content.

$$
\begin{aligned}
\theta & -K \text { correlation } \\
K & =K_{\mathrm{sat}} \Theta^{1 / 2}\left[1-\left(1-\Theta^{1 / m}\right)^{m}\right]^{2} \text { For } \psi<0 \\
& =K_{\text {sat }} \text { For } \psi \geq 0,
\end{aligned}
$$

where $K_{\text {sat }}$ is the soil saturated hydraulic conductivity.

\section{Root uptake model}

In the present study, the root water uptake $S(z, t)$ in eq. (1) is O-R model given by Ojha and Rai ${ }^{9}$. The soil water uptake rate $S_{\max }$ is given by non-linear O-R model given as

$$
S_{\max }=\left[\frac{T_{j}}{z_{r j}}(\beta+1)\left(1-\frac{z}{z_{r j}}\right)^{\beta}\right] \quad 0 \leq z \leq z_{\mathrm{rj}},
$$

where $T_{j}$ is the transpiration on $j$ th day, $\beta$ the nonlinearity coefficient, $z$ the depth below soil surface and $z_{r j}$ the root depth on $j$ th day. For $z=z_{r j}, S_{\max }$ value is zero (eq. (4)). $S_{\max }$ attains a maximum value at $z=0$.

\section{Initial and boundary conditions}

The solution of eq. (1) requires boundary conditions for specific solution. Initially the soil is assumed to have uniform pressure throughout its domain, i.e.

$$
\left.\begin{array}{l}
\psi=\psi_{\text {measured }}(z) \\
\psi=\psi_{f c}(z)
\end{array}\right\} \quad 0 \leq z \leq L, t=0
$$

where $\psi_{\text {measured }}(z)$ is the measured pressure head value in the field; $\psi_{f c}$ the pressure head corresponding to the field capacity (in absence of field measured values) and $L$ the length of solution domain.

Upper boundary condition (flux type) that includes soil evaporation $\left(E_{s}\right)$ at upper layer of soil and a Dirichlet type boundary condition during irrigation/rainfall were used in present study.

$$
\begin{aligned}
& \psi=\psi_{i / r} \quad z=L, \text { during irrigation/rainfall, } \\
& K(\psi)\left(\frac{\partial \psi}{\partial z}+1\right)=E_{s}, z=L, \text { in absence of irrigation, }
\end{aligned}
$$

where $\psi_{i / r}$ is the pressure head corresponding to saturated moisture content $(\psi=0)$, during irrigation or rainfall. The $E_{s}$ is partitioned component of the crop evapotranspiration $\left(E T_{c}\right)$.

At lower boundary, gravity drainage type condition is taken, i.e.

$$
-K(\psi)\left(\frac{\partial \psi}{\partial z}+1\right)=-K(\psi) \text { for } t \geq 0, z=0 .
$$

\section{Non-linear parameter $\beta$}

Shankar et $a l .{ }^{25}$ developed an empirical relationship for computation of non-linear parameter $\beta$ of O-R model using plant physiological parameters, i.e. maximum root depth, maximum daily transpiration and time to attain the maximum transpiration. The relationship developed is

$$
\beta=5.1128 T_{s}^{2}-6.117 T_{s}+3.1545 ; 0.07 \leq T_{s} \leq 0.98,
$$

where $T_{j \max }$ is the maximum value of daily transpiration; $Z_{r \text { max }}$ the maximum value of root depth; $t_{\text {peak }}$ the time to 
RESEARCH ARTICLES

Table 1. Locations of various agro climatic stations

\begin{tabular}{llcccl}
\hline Station & \multicolumn{1}{c}{ State } & Latitude & Longitude & Altitude (m) & Climate \\
\hline Roorkee & Uttarakhand & $29^{\circ} 52^{\prime} \mathrm{N}$ & $77^{\circ} 53^{\prime} \mathrm{E}$ & 274 & Semi-arid \\
Solan & Himachal Pradesh & $30^{\circ} 50^{\prime} \mathrm{N}$ & $77^{\circ} 11^{\prime} \mathrm{E}$ & 1260 & Sub-temperate sub-humid \\
Hamirpur & Himachal Pradesh & $31^{\circ} 68^{\prime} \mathrm{N}$ & $76^{\circ} 52^{\prime} \mathrm{E}$ & 738 & Humid sub-tropical \\
\hline
\end{tabular}

Table 2. Details of depth wise classification of soil and moisture characteristics

\begin{tabular}{|c|c|c|c|c|c|c|c|c|c|c|}
\hline Lysimeter & $\begin{array}{l}\text { Soil depth } \\
\quad(\mathrm{cm})\end{array}$ & $\begin{array}{c}\delta_{\text {bulk }} \\
(\mathrm{g} / \mathrm{cc})\end{array}$ & Gravel (\%) & Sand (\%) & Silt (\%) & Clay (\%) & $\begin{array}{l}\delta_{\text {particle }} \\
(\mathrm{g} / \mathrm{cc})\end{array}$ & $K_{\text {sat }}(\mathrm{cm} / \mathrm{h})$ & $\begin{array}{c}\theta_{\mathrm{fc}} \\
\left(\mathrm{cm}^{3} / \mathrm{cm}^{3}\right)\end{array}$ & $\begin{array}{c}\theta_{\mathrm{pwp}} \\
\left(\mathrm{cm}^{3} / \mathrm{cm}^{3}\right)\end{array}$ \\
\hline \multirow[t]{5}{*}{1} & $0-20$ & 1.52 & 17.1 & 43.4 & 28.2 & 11.3 & 2.62 & 1.02 & 0.208 & 0.068 \\
\hline & $20-40$ & 1.56 & 12.6 & 49.6 & 23.4 & 14.4 & 2.64 & 0.98 & 0.208 & 0.068 \\
\hline & $40-60$ & 1.62 & 11.3 & 46.3 & 24.8 & 17.6 & 2.58 & 0.95 & 0.208 & 0.068 \\
\hline & $60-80$ & 1.68 & 8.5 & 49.8 & 25.6 & 16.1 & 2.61 & 1.10 & 0.208 & 0.068 \\
\hline & $80-100$ & 1.72 & 19.8 & 42.4 & 23.2 & 14.6 & 2.60 & 1.35 & 0.208 & 0.068 \\
\hline \multirow{4}{*}{2} & $20-40$ & 1.30 & 40.4 & 39.6 & 35.2 & 25.6 & 2.54 & 0.90 & 0.230 & 0.120 \\
\hline & $40-60$ & 1.31 & 36.0 & 41.0 & 32.6 & 26.4 & 2.51 & 0.86 & 0.240 & 0.130 \\
\hline & $60-80$ & 1.35 & 20.0 & 39.6 & 36.4 & 24.0 & 2.48 & 0.80 & 0.240 & 0.120 \\
\hline & $80-100$ & 1.36 & 18.4 & 37.8 & 35.2 & 27.0 & 2.46 & 0.84 & 0.230 & 0.120 \\
\hline \multirow[t]{3}{*}{3} & $0-20$ & 1.51 & 27.0 & 54.9 & 23.8 & 21.1 & 2.54 & 2.96 & 0.220 & 0.070 \\
\hline & $20-40$ & 1.56 & 32.4 & 57.4 & 24.4 & 18.1 & 2.59 & 2.78 & 0.212 & 0.072 \\
\hline & $40-60$ & 1.63 & 24.7 & 59.2 & 24.3 & 16.4 & 2.61 & 2.44 & 0.208 & 0.058 \\
\hline
\end{tabular}

attain peak transpiration. $T_{s}$ the specific transpiration formulated as ${ }^{32}$

$$
T_{S}=\frac{T_{j \max }}{Z_{r \text { max }}} \times t_{\text {peak }} .
$$

\section{Numerical simulation}

The differential eq. (1) was solved using initial and boundary conditions given in eqs (5)-(8) for formulating a numerical code. For constitutive relationship eqs (2)(3) were used. The numerical model is based on a mass conservative, fully implicit finite difference scheme proposed by Celia et al. ${ }^{30}$. The solution includes spatial and temporal approximating in the equation by finite differences. Further, the non-linear equations is linearized by Picards' method ${ }^{33}$ and the resulting equation is solved using the Thomas algorithm ${ }^{34}$. At successive advancing times, the model yields spatial distribution of pressure head and moisture content of the soil in the crop root zone (CRZ). The model computed moisture contents, moisture depletion values at different root zone depths.

\section{Description of agro-climates}

The present study is focused on the utility of O-R model in predicting soil moisture dynamics in CRZ and establishing its efficacy across different agro-climates having variations in meteorological parameters and soil properties. Table 1 lists the details of the agro-climatic locations considered in the study. Field crop experiments conducted under controlled conditions by Shankar et al. ${ }^{25}$ at Roorkee and Kumar et al. ${ }^{17}$ at Solan for three major crops, i.e. maize, wheat and Indian mustard were used as secondary data in the present study. Field experiments on maize, wheat and Indian mustard for present study were conducted at Hamirpur and are used as primary data.

\section{Details of experimental setup}

Lysimeters were installed for field crop experiments at Roorkee (hereinafter this study is referred as LS-1), Solan (hereinafter this study is referred as LS-2) and Hamirpur (hereinafter this study is referred as LS-3). LS-1 was installed at Field Research Station of Civil Engineering Department, Indian Institute of Technology Roorkee (Uttarakhand, India). LS-2 was installed at the experimental station of Dr Y. S. Parmar University of Horticulture and Forestry, Solan (Himachal Pradesh, India). LS-3 was installed in the Agricultural Experimental Station of Civil Engineering Department, National Institute of Technology Hamirpur (Himachal Pradesh, India). Two drainage Lysimeters (150 $\mathrm{cm}$ deep with a surface area of 1 sq. $\mathrm{m}$ ) were installed in an open field at each station to simulate actual field dynamics under controlled conditions. Soil within the Lysimeters was kept same as that of surrounding agricultural plot. Details of soil texture for 


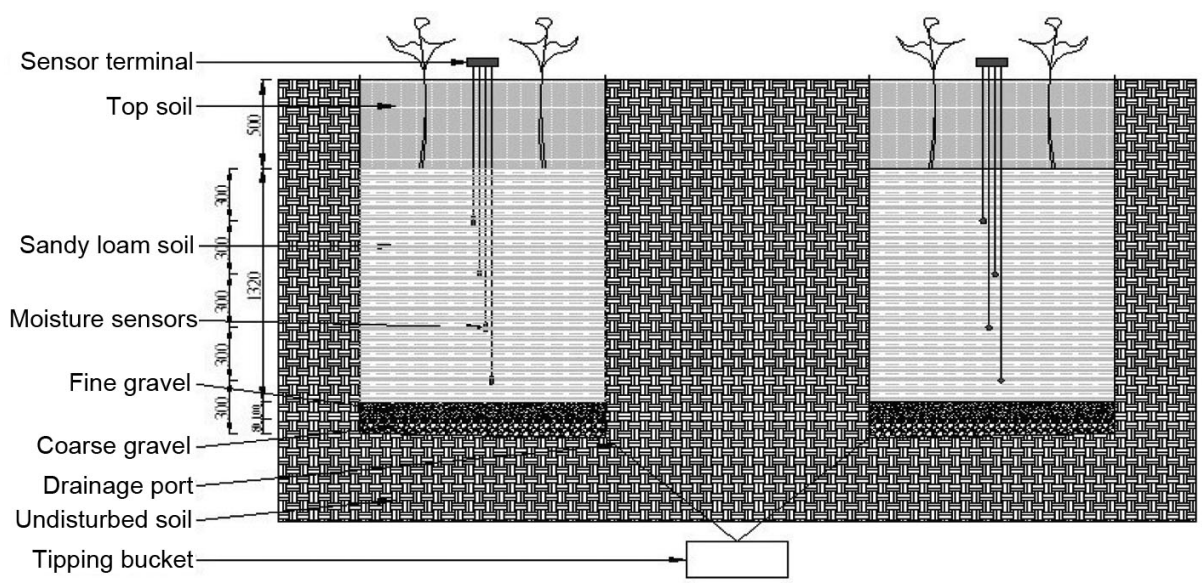

Figure 1. Representation of Lysimeter setup in experimental station.

Table 3. Details of the field crop experimental data

\begin{tabular}{|c|c|c|c|c|c|c|c|c|c|c|}
\hline \multirow[b]{2}{*}{ Crops } & \multirow[b]{2}{*}{ Variety sown } & \multirow[b]{2}{*}{ Date of sowing } & \multirow{2}{*}{$\begin{array}{c}\text { Date of } \\
\text { harvesting }\end{array}$} & \multirow{2}{*}{$\begin{array}{l}\text { Duration } \\
\text { (days) }\end{array}$} & \multicolumn{4}{|c|}{ Growth stages (days) } & \multirow{2}{*}{$\begin{array}{c}\text { Irrigation } \\
\text { provided (day) }\end{array}$} & \multirow{2}{*}{$\begin{array}{l}\text { Spacing } \\
(\mathrm{cm})\end{array}$} \\
\hline & & & & & I & II & III & IV & & \\
\hline Maize (Zea mays) & $\begin{array}{l}\text { Maize } 7074 \\
\text { (Hybid) }\end{array}$ & 1 May 2014 & 22 August 2014 & 114 & 20 & 34 & 36 & 24 & $\begin{array}{l}\text { 22nd, 36th, 48th } \\
\text { and 64th }\end{array}$ & $50 \times 20$ \\
\hline $\begin{array}{l}\text { Wheat } \\
\text { (Triticum aestivum) }\end{array}$ & $\begin{array}{l}\text { Super } \\
(6776 / \mathrm{PB})\end{array}$ & $\begin{array}{l}30 \text { November } \\
2014\end{array}$ & 2 May 2015 & 154 & 30 & 46 & 50 & 28 & $\begin{array}{l}\text { 26th, 44th, 56th, } \\
\text { 80th, 96th } \\
\text { and 116th }\end{array}$ & $25 \times 5$ \\
\hline $\begin{array}{l}\text { Indian mustard } \\
\qquad \text { (Brassica Juncea) }\end{array}$ & $\begin{array}{l}\text { Indian mustard } \\
\text { VL-804 }\end{array}$ & $\begin{array}{l}4 \text { November } \\
2015\end{array}$ & $\begin{array}{l}25 \text { February } \\
2016\end{array}$ & 114 & 19 & 32 & 38 & 25 & $\begin{array}{l}11 \text { th, } 25 \text { th, } 37 \text { th, } \\
59 \text { th and } 91 \mathrm{st}\end{array}$ & $40 \times 15$ \\
\hline
\end{tabular}

each agro-climate are mentioned in Table 2. Coarse gravel of size more than $3 \mathrm{~cm}$ diameter at bottom and above it $12 \mathrm{~cm}$ was filled with fine gravel to avoid clogging and to facilitate the drainage towards the pipe. Soil moisture measurement sensors were embedded at different depths. These were installed at depths of 20 , 40, 60, 80 and $100 \mathrm{~cm}$. In Lysimeter set up percolation to the groundwater table from the root zone is represented by the drainage. Figure 1 shows the vertical layout of LS-3.

\section{Soil characteristics}

Soil samples were collected from the respective experimental site. Samples were subjected to a detailed grain size analysis using a set of standard sieves and a calibrated hydrometer ${ }^{35}$. Saturated hydraulic conductivity $\left(K_{\text {sat }}\right)$ is determined using Guelph Permeameter $(\mathrm{M} / \mathrm{s}$ Meter Group, USA). Table 2 shows the depth wise textural classification, bulk density $\left(\delta_{\text {bulk }}\right)$, particle density $\left(\delta_{\text {particle }}\right), K_{\text {sat }}$, field capacity $\left(\theta_{\text {fc }}\right)$, and permanent wilting point $\left(\theta_{\text {pwp }}\right)$ for the three different agro-climates considered in this study. A significant difference in soil moisture parameters for different agro-climates has been observed.
Soil moisture characteristic (SMC) curve $^{36}$ represents the functional relationship between the volumetric moisture content $(\theta)$ and the pressure head $(\psi)$ in the unsaturated porous medium. The SMC curve for LS-1 and LS-2 is given in Shankar ${ }^{14}$ and Kumar et al. ${ }^{17}$ respectively. In case of LS-3, experimental SMC is obtained using pressure plate apparatus (M/s Soil Moisture Equipment Corporation, USA). The experimental SMC is well described by realistic Van-Genuchten ${ }^{31}$ model, with values of unsaturated soil hydraulic parameters $\theta_{r}, \theta_{s}, \alpha_{v}$ and $n_{v}$ as $0.056 \mathrm{~cm}^{3} \mathrm{~cm}^{-3}, 0.36 \mathrm{~cm}^{3} \mathrm{~cm}^{-3}, 5.9 \mathrm{~m}^{-1}$ and 1.83 respectively. Figure 2 expresses the functional relationship between $\theta$ and $\psi$ in SMC curve for the present study.

\section{Crop details}

The entire crop growth period for the wheat, maize and Indian mustard was divided into four ${ }^{37}$ stages (initial, crop development, midseason and late season). Table 3 gives the details of crop duration, crop stages, spacing and irrigation events pertaining to these crops for field experiments conducted at Hamirpur.

Leaf area index (LAI) values, which are required for the partitioning of the $E T_{\mathrm{c}}$ into plant transpiration and soil evaporation, were measured by the direct method. Root 
depth was measured by the trench profile method complimented with the field-observed soil moisture depletion method $^{38}$. Crop height was measured by taking the average of 10 plants selected at random. During the initial stages, the plant height, root depth and LAI were

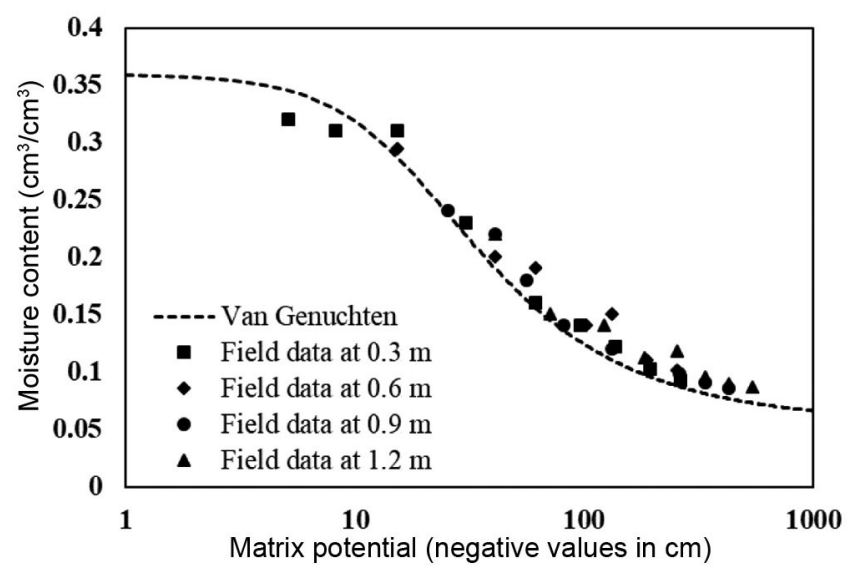

Figure 2. Depth wise moisture content-suction head data with fitted SMC for field soil.

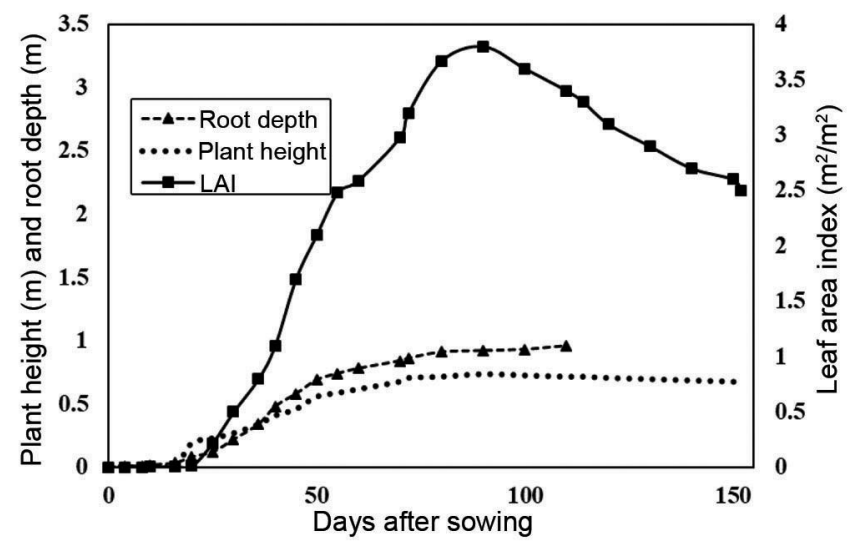

Figure 3. Root depth, plant height and leaf area index variation of maize.

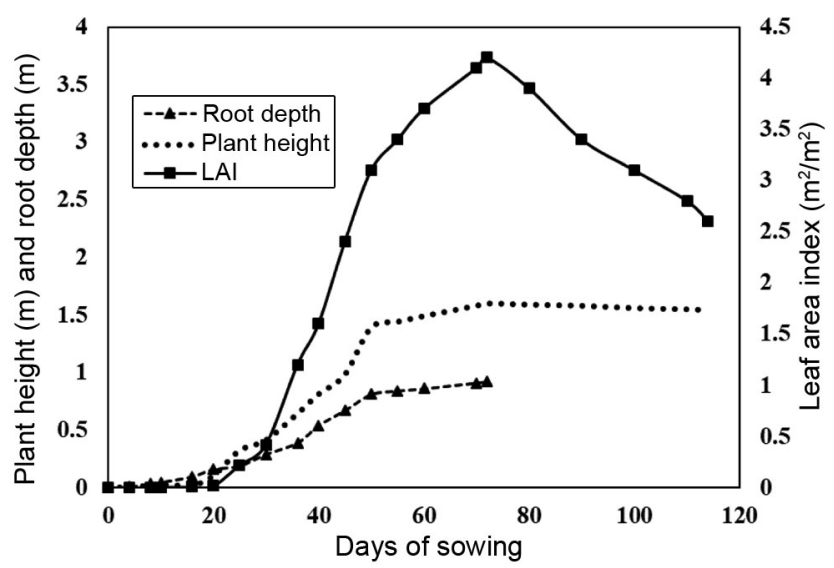

Figure 4. Root depth, plant height and leaf area index variation of wheat. measured at 10-12 day intervals; at later stages, this interval was reduced to 7 days. Figures 3-5 show the plant height, root depth and LAI for maize, wheat and Indian mustard for LS-3. The plant height, root depth and LAI for maize, wheat and Indian mustard for LS-1 and LS-2 are detailed in Shankar et al. ${ }^{25}$ and Kumar et al. ${ }^{17}$ respectively.

\section{Crop water requirements}

Crop evapotranspiration $\left(E T_{c}\right)$ is determined as the product of daily crop coefficient $\left(K_{c}\right)$ and reference evapotranspiration $\left(E T_{0}\right)$. FAO-56 Penman-Monteith ${ }^{39-42}$ equation is used to compute $E T_{0}$ for the present study. The meteorological data (temperature, humidity, rainfall, solar radiation and wind speed) required for the estimation of $E T_{0}$ was recorded with the help of Automatic Weather Station located at National Institute of Technology, Hamirpur. Penman-Monteith equation is given as

$$
E T_{0}=\frac{0.408 \Delta\left(R_{n}-G\right)+\gamma \frac{900}{\bar{T}+273} u\left(e_{s}-e_{0}\right)}{\Delta+\gamma(1+0.34 u)},
$$

where $R_{n}$ is net radiation at the crop surface $\left(\mathrm{MJ} \mathrm{m}^{-2}\right.$ day $\left.^{-1}\right)$, $G$ the soil heat flux density $\left(\mathrm{MJ} \mathrm{m}^{-2}\right.$ day $\left.^{-1}\right), T$ the mean daily air temperature at $2 \mathrm{~m}$ height $\left({ }^{\circ} \mathrm{C}\right), u_{2}$ the wind speed at $2 \mathrm{~m}$ height $\left(\mathrm{m} \mathrm{s}^{-1}\right), e_{s}$ the saturation vapour pressure $(\mathrm{kPa}), e_{a}$ the actual vapour pressure $(\mathrm{kPa}), e_{s}-e_{a}$ the saturation vapour pressure deficit $(\mathrm{kPa}), \Delta$ the slope of vapour pressure curve $\left(\mathrm{kPa}^{\circ} \mathrm{C}^{-1}\right)$ and $\gamma$ is the psychrometric constant $\left(\mathrm{kPa}{ }^{\circ} \mathrm{C}^{-1}\right)$.

Soil evaporation $\left(E_{s}\right)$ is obtained as the partitioned component of $E T_{c}$ using relationship proposed by Eberbach and $\mathrm{Pala}^{43}$ given as

$$
E_{s} / E T_{c}=\exp (-\delta * \mathrm{LAI})
$$

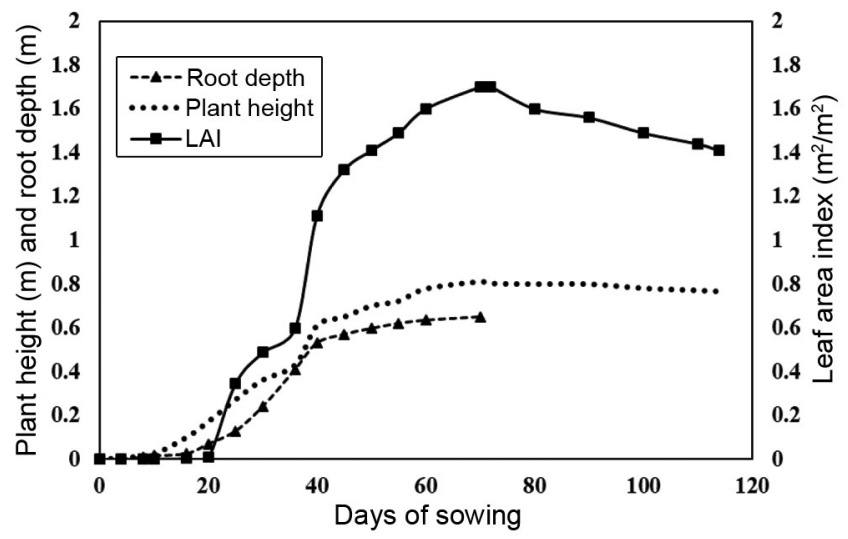

Figure 5. Root depth, plant height and leaf area index variation of Indian mustard. 


\section{RESEARCH ARTICLES}

$\delta$ is empirical coefficient whose value is $0.58,0.47$ and 0.50 for maize, wheat and Indian mustard respectively ${ }^{44-46}$. The modified values of $K_{c \text { ini }}, K_{c}$ mid and $K_{c}$ end are 0.41 , 1.79 and 0.51 for maize, $0.58,1.17$ and 0.40 for wheat and $0.56,1.16$ and 0.31 for Indian mustard. The partition of $E T_{c}$ into plant transpiration and soil evaporation for Indian mustard is shown in Figure 6.

\section{Model performance indicators}

Performance of the field-observed and model-predicted percentage moisture depletion for the present study is evaluated using coefficient of determination $\left(R^{2}\right)^{47}$, Nash-Sutcliffe efficiency (NSE) ${ }^{48}$ and mean bias error $(\mathrm{MBE})^{49} \cdot R^{2}$ denotes the degree of linear dependency, NSE is used to verify the credibility of models and that the maximum value for both evaluation indices is 1 whereas MBE signifies the over or under estimation capacity of the model. The performance of a model is considered better when $R^{2}$ and NSE are higher and MBE is lower having small range of values. The equations for these indicators are given as

$$
\begin{aligned}
& R^{2}=\frac{\sum_{c r=1}^{n}\left(\theta_{f i}-\overline{\theta_{f i}}\right)\left(\theta_{m i}-\overline{\theta_{m i}}\right)}{\sqrt{\sum_{i=1}^{n}\left(\theta_{f i}-\overline{\theta_{f i}}\right)} \sqrt{\sum_{i=1}^{n}\left(\theta_{m i}-\overline{\theta_{m i}}\right)^{2}}}, \\
& \mathrm{NSE}=1-\frac{\sum_{i=1}^{n}\left(\theta_{f i}-\theta_{m i}\right)^{2}}{\sum_{i=1}^{n}\left(\theta_{f i}-\overline{\theta_{f i}}\right)^{2}}, \\
& \mathrm{MBE}=n^{-1} \sum_{i=1}^{n} e_{i}=\overline{\theta_{m i}}-\overline{\theta_{f i}},
\end{aligned}
$$

where $n$ is the number of observations, $\theta_{f i}, \theta_{m i}$ the fieldobserved and model-predicted values, $\overline{\theta_{f i}}, \overline{\theta_{m i}}$ the fieldobserved and model-predicted average values.

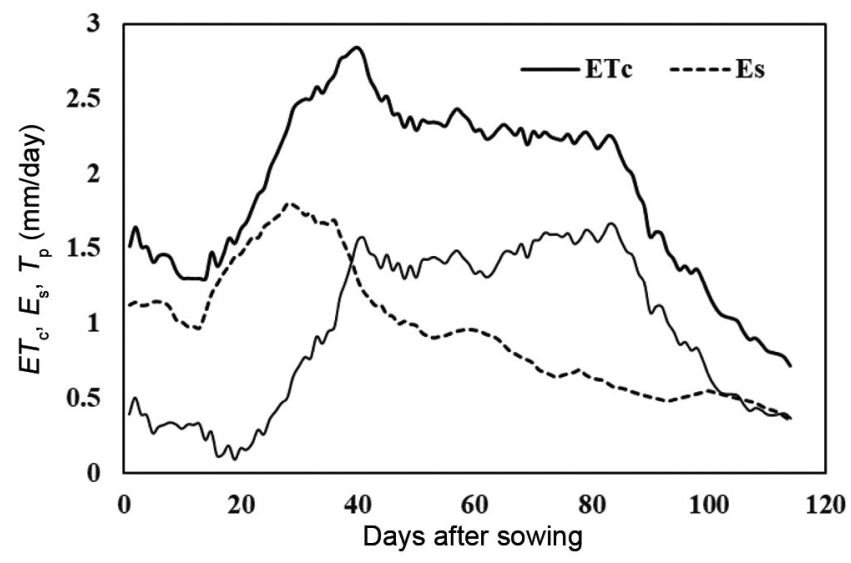

Figure 6. Daily crop evapotranspiration, evaporation and transpiration for Indian mustard.

\section{Results and discussion}

The efficacy of O-R model in simulating soil moisture dynamics in the CRZ is investigated through qualitative and quantitative evaluation. The qualitative evaluation is performed through graphical comparisons between fieldobserved and model predicted values. The quantitative evaluation is based on model performance indicators as explained earlier. The parameters considered for evaluation are percentage soil moisture depletion within two wetting events, soil moisture profile along depth for a particular time and soil moisture variation throughout the crop period at different depths.

\section{Non-linear parameter computation}

The parameter $\beta$ in the O-R model characterizes the nonlinearity in RWU, and determines the type of irrigation and fertilizer application activities that would be most efficient in terms of plant use. The empirical equation (eq. (9)) was used to compute the values of $\beta$ for maize, wheat and Indian mustard in all three agro-climates. Table 4 shows the detail of parameters used in $\beta$ calculation.

\section{Depletion of soil moisture at different depth}

Soil moisture depletion (SMD) determined from the CRZ of maize, wheat and Indian mustard for LS-1, LS-2 and LS-3 were used to analyse the moisture uptake efficacy of the model. Comparison of model-predicted SMD values in the CRZ with field-observed values for maize, wheat and Indian mustard for the three agro-climates were plotted.

The comparison for maize for different locations is shown in Figure 7, whereas for wheat it is shown in Figure 8 . The model-predicted values are found to have reliable agreement with field-observed values for three different agro-climates.

The quantitative evaluation between the field-observed and model-predicted SMD in the CRZ was carried out using model performance indicators, and the results of the evaluation are summarized in Table 5. The $R^{2}$ values for maize, wheat and Indian mustard at Hamirpur ranged between 0.65 and $0.71,0.70$ and 0.75 and 0.69 and 0.73 respectively. For Roorkee and Solan, it ranged from 0.65 to 0.71 (maize); 0.67 to 0.73 (wheat); 0.69 to 0.72 (Indian mustard) and 0.68 to 0.73 (maize); 0.66 to 0.74 (wheat); 0.68 to 0.72 (Indian mustard) respectively. The NSE values were, maize: $0.69-0.73$, wheat: $0.70-0.73$ and Indian mustard: $0.72-0.74$ at Hamirpur, whereas for Roorkee and Solan, it was 0.67-0.70 (maize); 0.68-0.74 (wheat); $0.70-0.74$ (Indian mustard) and 0.68-0.72 (maize); 0.660.73 (wheat); 0.69-0.73 (Indian mustard) respectively. 
RESEARCH ARTICLES

Table 4. Optimal non-linearity coefficients for maize, wheat and Indian mustard for LS-3

\begin{tabular}{lccccc}
\hline Crop & $T_{j \max }\left(\mathrm{mm} \mathrm{day}^{-1}\right)$ & $Z_{r \max }(\mathrm{m})$ & $t_{\text {peak }}($ days $)$ & Specific transpiration $\left(T_{s}\right)$ & $\beta$ \\
\hline Maize & 6.06 & 0.92 & 72 & 0.474 & 1.40 \\
Wheat & 3.86 & 0.96 & 91 & 0.366 & 1.60 \\
Indian mustard & 1.8 & 0.65 & 70 & 0.194 & 2.16 \\
\hline
\end{tabular}

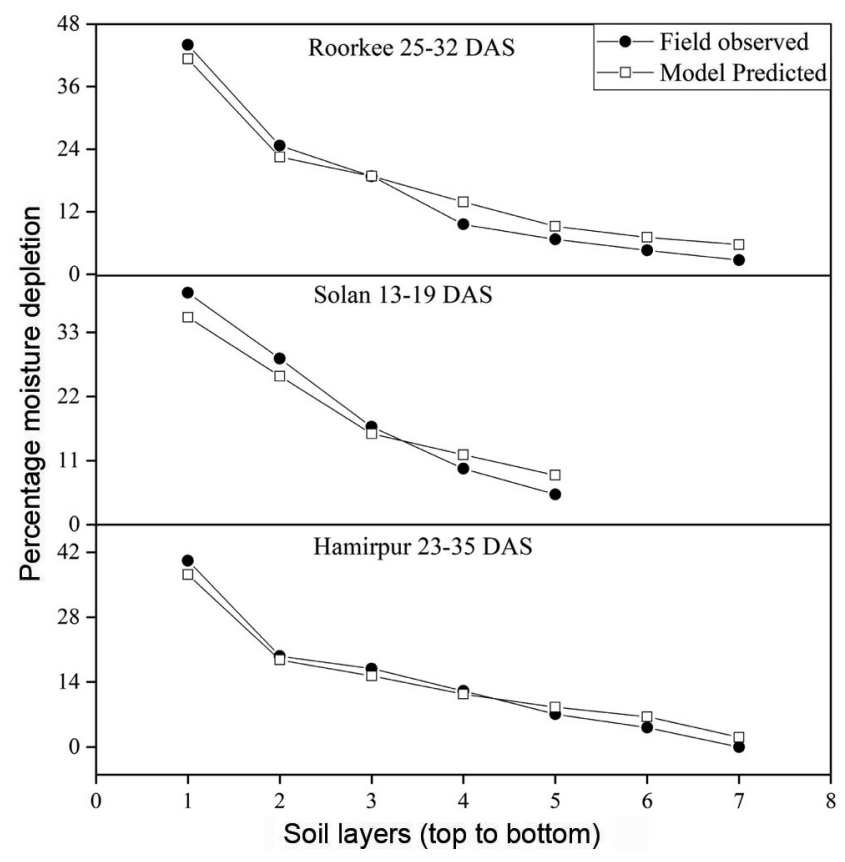

Figure 7. Comparison of field-observed and model predicted soil moisture depletion between different periods of maize for different locations.

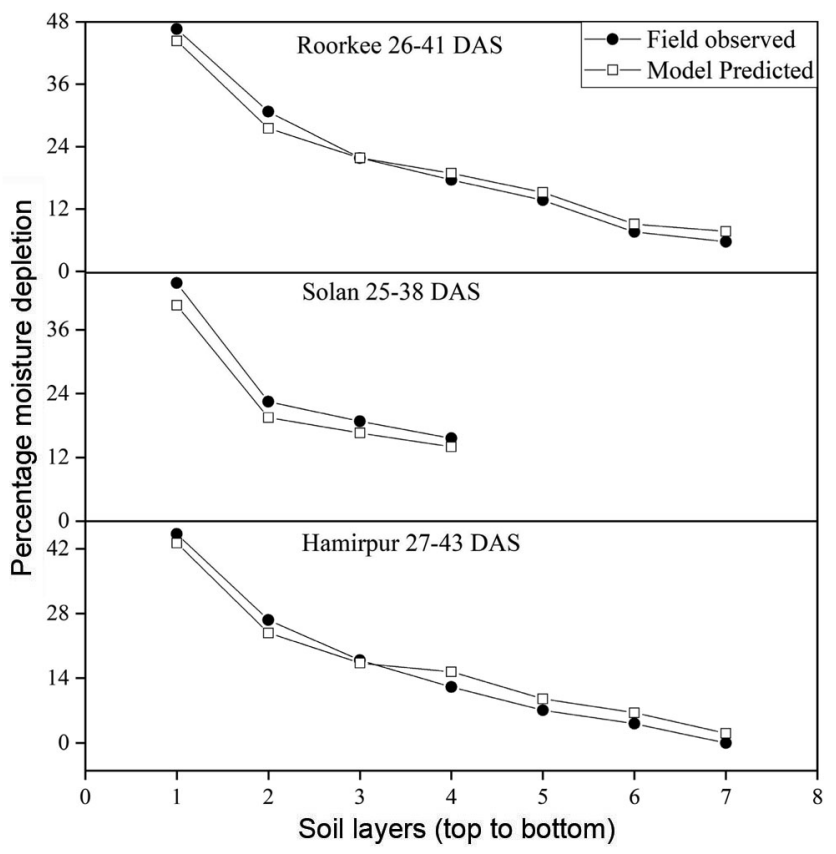

Figure 8. Comparison of field-observed and model predicted soil moisture depletion between different periods of wheat for different locations.

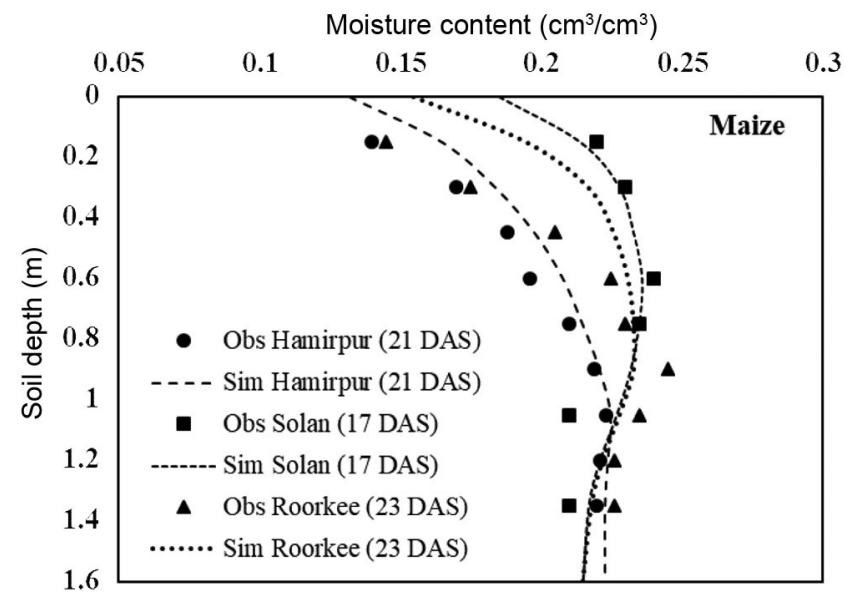

Figure 9. Comparison of field-observed and model predicted soil moisture profiles of maize in different agro climatic zone.

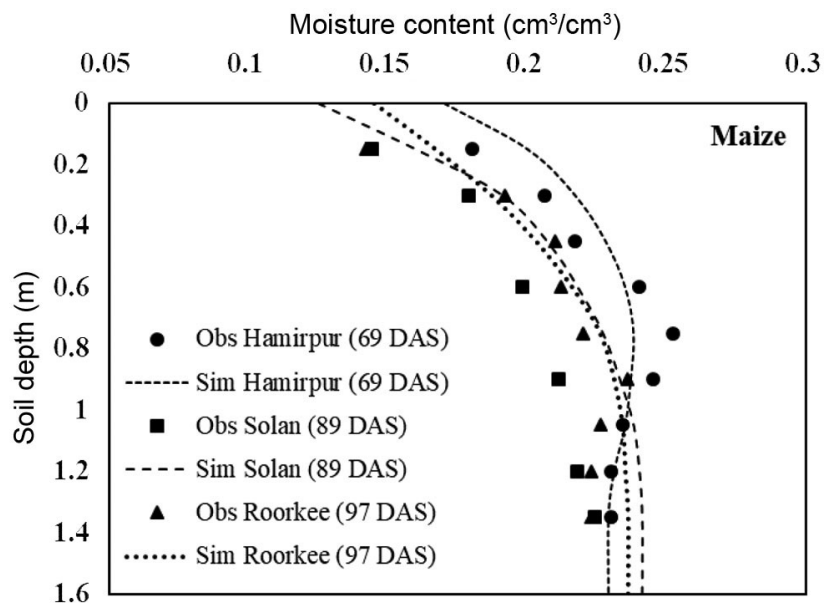

Figure 10. Comparison of field-observed and model predicted soil moisture profiles of maize in different agro climatic zone.

The MBE values were, maize: -0.11 to 0.15 , wheat: -0.15 to 0.14 and Indian mustard: -0.14 to 0.18 at Hamirpur whereas for Roorkee and Solan, it was -0.13 to 0.17 (maize); -0.19 to 0.16 (wheat); -0.14 to 0.13 (Indian mustard) and -0.14 to 0.16 (maize); -0.15 to 0.17 (wheat); -0.14 to 0.12 (Indian mustard) respectively. Error statistics of model-predicted and field-observed SMD at different stages of growth period for various crops showed good agreement for three different agroclimates. 
RESEARCH ARTICLES

Table 5. Error Statistics of soil moisture depletion at different times of growth period for maize, wheat and Indian mustard

\begin{tabular}{|c|c|c|c|c|c|c|c|c|c|c|c|c|}
\hline \multirow{2}{*}{$\begin{array}{l}\text { Location } \\
\text { Crop name }\end{array}$} & \multicolumn{4}{|c|}{ Roorkee } & \multicolumn{4}{|c|}{ Solan } & \multicolumn{4}{|c|}{ Hamirpur } \\
\hline & $\begin{array}{l}\text { Period } \\
\text { (DAS) }\end{array}$ & $R^{2}$ & NSE & $\mathrm{MBE}$ & $\begin{array}{l}\text { Period } \\
\text { (DAS) }\end{array}$ & $R^{2}$ & NSE & MBE & $\begin{array}{l}\text { Period } \\
\text { (DAS) }\end{array}$ & $R^{2}$ & NSE & $\mathrm{MBE}$ \\
\hline \multirow[t]{3}{*}{ Maize } & $25-32$ & 0.65 & 0.67 & -0.13 & $13-19$ & 0.68 & 0.72 & -0.14 & $23-35$ & 0.67 & 0.73 & -0.11 \\
\hline & $34-41$ & 0.66 & 0.69 & 0.14 & $56-65$ & 0.73 & 0.68 & 0.16 & $37-47$ & 0.65 & 0.69 & 0.13 \\
\hline & $43-50$ & 0.71 & 0.70 & 0.17 & $85-90$ & 0.69 & 0.70 & 0.13 & $49-63$ & 0.71 & 0.72 & 0.15 \\
\hline \multirow[t]{3}{*}{ Wheat } & $26-41$ & 0.67 & 0.68 & 0.14 & $25-38$ & 0.69 & 0.66 & 0.17 & $27-43$ & 0.70 & 0.71 & 0.14 \\
\hline & $57-72$ & 0.68 & 0.71 & 0.16 & $50-68$ & 0.66 & 0.68 & 0.13 & $45-55$ & 0.73 & 0.73 & 0.13 \\
\hline & $97-105$ & 0.73 & 0.74 & -0.19 & $92-105$ & 0.74 & 0.73 & -0.15 & $57-79$ & 0.75 & 0.70 & -0.15 \\
\hline \multirow[t]{2}{*}{ Indian mustard } & $24-42$ & 0.72 & 0.70 & 0.13 & $22-38$ & 0.68 & 0.69 & 0.12 & $32-46$ & 0.69 & 0.72 & 0.18 \\
\hline & $65-84$ & 0.69 & 0.74 & -0.14 & $48-68$ & 0.72 & 0.73 & -0.14 & $52-70$ & 0.73 & 0.74 & -0.14 \\
\hline
\end{tabular}

$R^{2}$, coefficient of determination; NSE, Nash-Sutcliffe efficiency; MBE, Mean bias error.

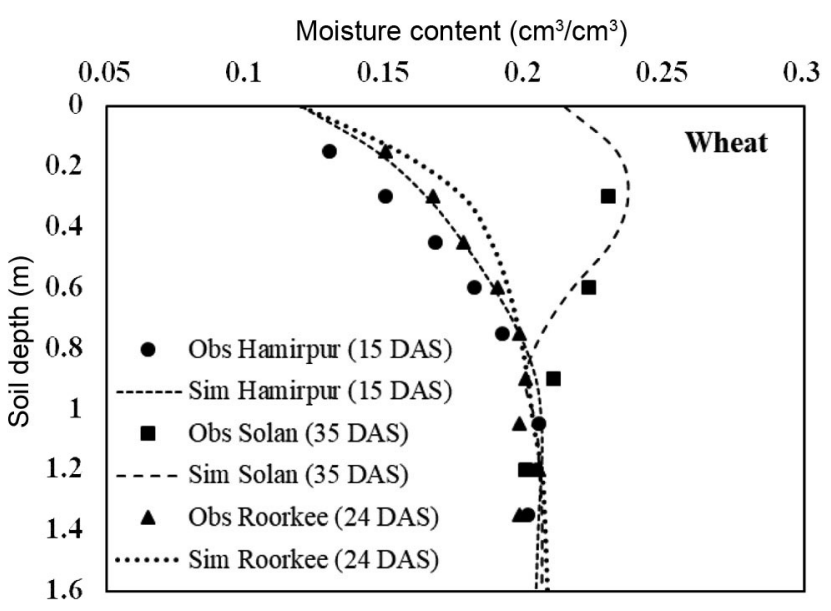

Figure 11. Comparison of field-observed and model predicted soil moisture profiles of wheat in different agro climatic zone.

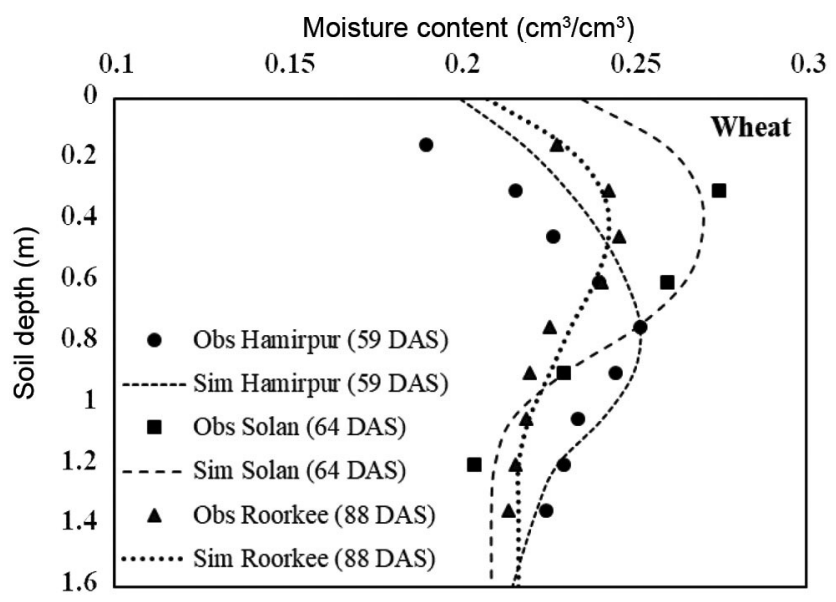

Figure 12. Comparison of field-observed and model predicted soil moisture profiles of wheat in different agro climatic zone.

It is evident from Figures 7 and 8 and error statistics range discussed above that the differences between model-predicted and field-observed SMD values in the middle layers are less pronounced. In active root zone of the crops, based on the observation from the modelpredicted SMD patterns, the model underestimates the SMD in the top layers and overestimates the moisture depletion in bottom layers. However, it is notable that this tendency significantly diminishes in the durations falling in the development and mid-season crop stages. Both these stages are important from the point of precise estimation of crop water requirement.

\section{Soil moisture profile in crop root zone}

The comparison of model-predicted and field-observed soil moisture profiles in the CRZ establishes the existence of non-linearity in RWU. For brevity, fieldobserved and model-predicted soil moisture profiles in the root zone at discrete times in the crop period were plotted for maize, wheat and Indian mustard for the considered agro-climates. Figures 9-12 illustrate the pattern of soil moisture variation in the root zone on particular days for maize and wheat respectively, well establishes the existence of non-linearity in RWU and confirms the qualitative agreement between field-observed and modelpredicted profiles.

For Roorkee, the error statistics for maize is in the range of; $R^{2}: 0.65$ to 0.69 , NSE: 0.68 to 0.72 , MBE: -0.18 to 0.13 , for wheat; $R^{2}: 0.66$ to 0.72 , NSE: 0.67 to 0.71 and MBE: -0.17 to 0.14 and for Indian mustard; $R^{2}: 0.67$ to 0.73 , NSE: 0.65 to 0.70 and MBE: -0.15 to 0.15 . For Solan, the error statistics in case of maize follow the range; $R^{2}$ : 0.66 to 0.71 , NSE: 0.68 to 0.72 and MBE: -0.13 to 0.15 and in case of wheat follow the range; $R^{2}$ : 0.67 to 0.71 , NSE: 0.65 to 0.71 and MBE: -0.14 to 0.13 and in case of Indian mustard follow the range; $R^{2}: 0.66$ to 0.71 , NSE: 0.65 to 0.69 and MBE: -0.15 to 0.14 . For Hamirpur, the error statistics for maize; $R^{2}: 0.69$ to 0.73 , NSE: 0.68 to 0.73 and MBE: -0.19 to 0.13 , for wheat; $R^{2}$ : 0.67 to 0.72 , NSE: 0.68 to 0.73 and MBE: -0.17 to 0.16 and for Indian mustard; $R^{2}: 0.65$ to 0.68 , NSE: 0.67 to 

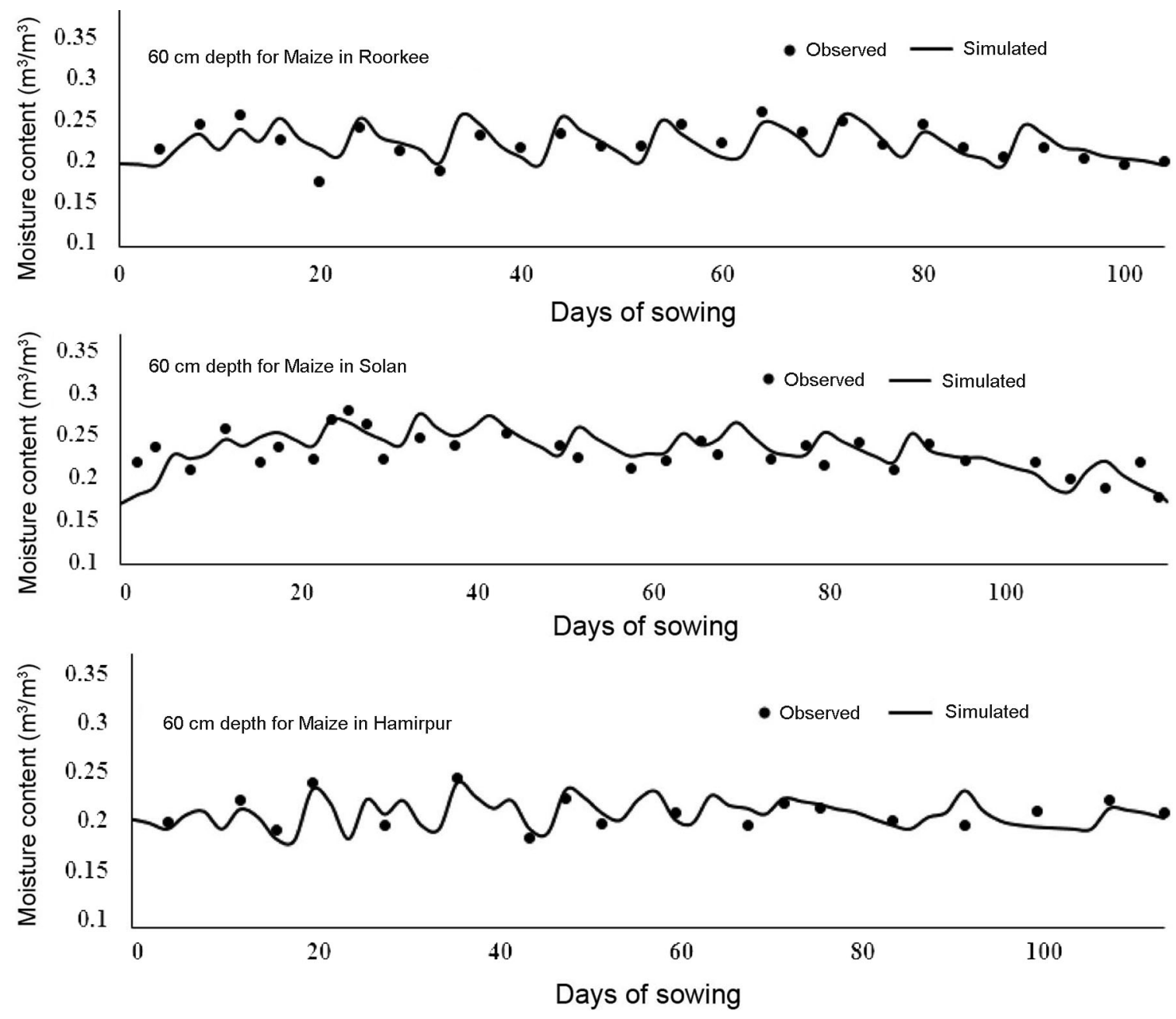

Figure 13. Field-observed and model-predicted soil moisture status for the entire crop period for maize at $60 \mathrm{~cm}$ depth for different agro-climate zones.

0.70 and MBE: -0.15 to 0.13 . The $R^{2}$ and NSE values are found above 0.65 , which shows the good agreement between model-predicted and field-observed profiles, referring to the satisfactory consideration of O-R model for practical applications in various agro-climates. Also, the range of MBE values in the three agro-climates is low. Hence all three agro-climates considered in this study, gave satisfactory results.

\section{Soil moisture status at various root zone depths}

Soil moisture variation at different depths of CRZ elaborates the accessibility of moisture for plant moisture uptake which indicates the part of CRZ, most susceptible to moisture depletion. The moisture status at various root zone depths at which soil moisture measurement sensors were embedded was compared with the corresponding model-predicted soil moisture status of maize, wheat and Indian mustard for three agro-climates. Generally, in the upper parts of the root zone having high root density, moisture depletes comparatively faster than deeper parts of the root zone. The model-predicted and field-observed soil moisture variation for 60 and $30 \mathrm{~cm}$ depths of maize and wheat respectively are shown in Figures 13 and 14. It is evident from Figures 13 and 14 that model-predicted soil moisture variation at a particular depth throughout the crop period shows good agreement with the fieldobserved soil moisture content values during the crop period of both crops for three agro-climates. Table 6 shows the comparative error statistics for model-predicted and field-observed values. The $R^{2}$ value for various root zone depths were above 0.65 which depicts good agreement between model-predicted and field-observed values. It was observed that the other two performance parameters, NSE and MBE gave satisfactory values too. These observations on the values of statistical parameters $R^{2}$, NSE, and MBE for the soil moisture status at particular depth for three agro-climates indicate that the nonlinearity of RWU is well predicted using O-R model. 


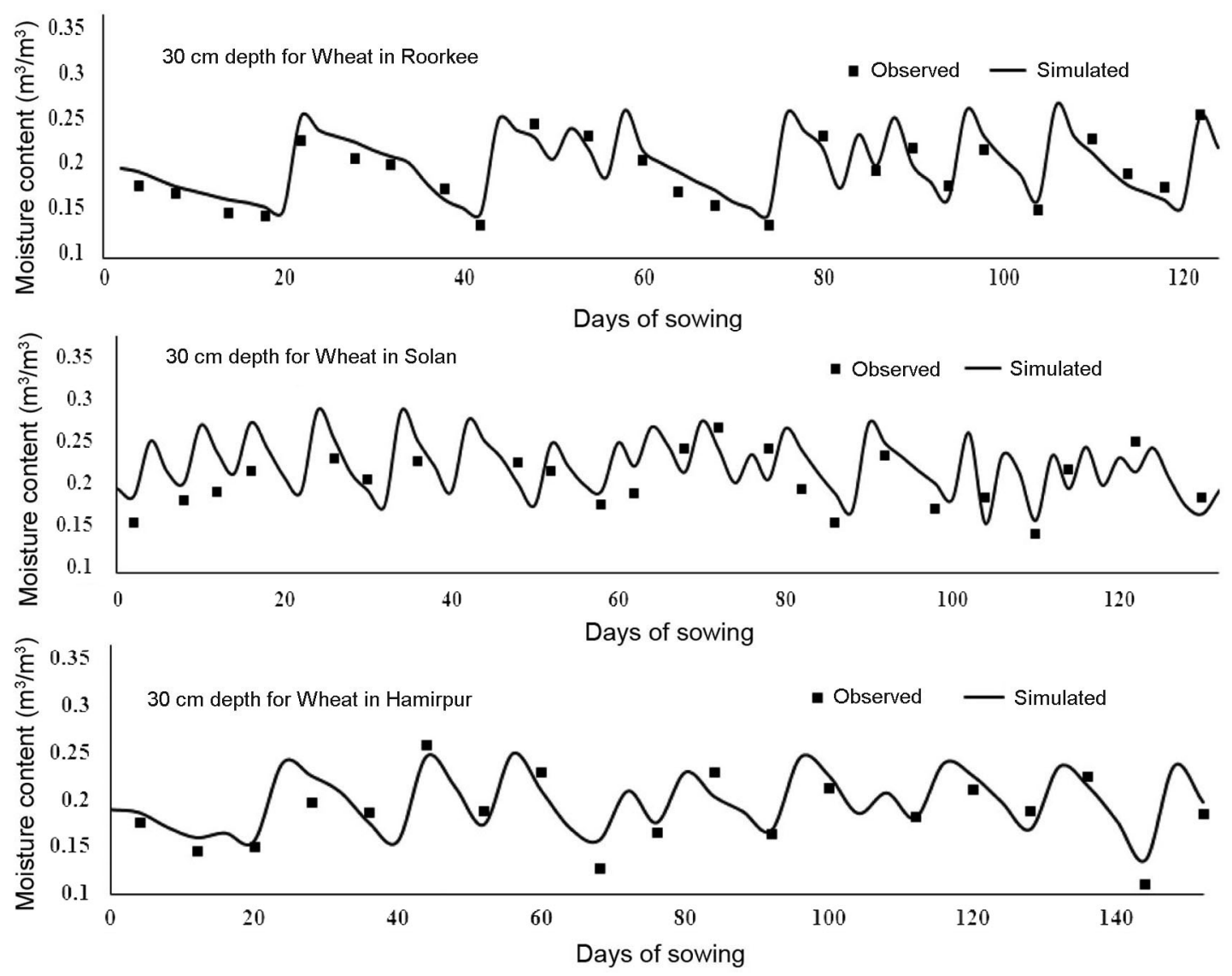

Figure 14. Field-observed and model-predicted soil moisture status for the entire crop period for wheat at $30 \mathrm{~cm}$ depth for different agro-climate zones.

Table 6. Comparison of field observed and model-predicted error statistics for soil moisture status at different depths of maize and wheat and mustard for different agro climatic zone

\begin{tabular}{|c|c|c|c|c|c|c|c|c|c|c|}
\hline \multirow{2}{*}{$\begin{array}{l}\text { Location } \\
\text { Crop name }\end{array}$} & \multirow[b]{2}{*}{ Soil depth } & \multicolumn{3}{|c|}{ Roorkee } & \multicolumn{3}{|c|}{ Solan } & \multicolumn{3}{|c|}{ Hamirpur } \\
\hline & & $R^{2}$ & NSE & MBE & $R^{2}$ & NSE & MBE & $R^{2}$ & NSE & MBE \\
\hline \multirow{2}{*}{ Maize } & $0.2-0.4$ & 0.70 & 0.68 & -0.19 & 0.70 & 0.69 & 0.14 & 0.65 & 0.67 & 0.16 \\
\hline & $0.4-0.6$ & 0.72 & 0.69 & 0.16 & 0.72 & 0.68 & 0.13 & 0.69 & 0.66 & 0.14 \\
\hline \multirow{3}{*}{ Wheat } & $0.2-0.4$ & 0.70 & 0.69 & -0.16 & 0.69 & 0.66 & 0.14 & 0.67 & 0.71 & 0.21 \\
\hline & $0.4-0.6$ & 0.67 & 0.66 & 0.14 & 0.71 & 0.69 & 0.16 & 0.69 & 0.72 & 0.237 \\
\hline & $0.6-0.8$ & 0.72 & 0.71 & 0.17 & 0.69 & 0.70 & 0.15 & 0.70 & 0.69 & 0.143 \\
\hline \multirow[t]{2}{*}{ Indian mustard } & $0-0.2$ & 0.66 & 0.67 & -0.21 & 0.68 & 0.66 & 0.23 & 0.67 & 0.65 & 0.13 \\
\hline & $0.2-0.4$ & 0.67 & 0.66 & 0.23 & 0.67 & 0.69 & 0.19 & 0.69 & 0.68 & 0.15 \\
\hline
\end{tabular}

\section{Conclusion}

In present study, the moisture prediction efficiency of non-linear O-R model was evaluated for semi-arid (Roorkee), sub-temperate sub-humid (Solan) and humid subtropical (Hamirpur) agro-climates. A numerical code was developed for computing RWU and simulating soil mois- ture dynamics in the CRZ. Field crop experiments on maize, wheat and Indian mustard were performed in humid sub-tropical agro-climate and secondary data for other two agro-climates were considered. Graphical comparisons and error statistics provide reliable agreement between percentage SMD (between two wetting events), soil moisture profile (along depth) and soil moisture variation 
(throughout crop period) for crops considered under different agro-climates. Results of comparative analysis indicate that $\mathrm{O}-\mathrm{R}$ model is efficient in predicting moisture extraction from crops under different agro-climates. The study postulates that the non-linearity in RWU is well represented by the optimal value of parameter $\beta$.

Disclosure statement: No potential conflict of interest was reported by the authors.

1. World Water Assessment Programme, United Nations World Water Development Report: water for a sustainable world. United Nations Educational, Scientific and Cultural Organization, Paris, 2015.

2. Green, S. R., Vogeler, I., Clothier, B. E., Mills, T. M. and van den Dijssel, C., Modelling water uptake by mature apple tree. Aust. J. Soil Res., 2003, 41(3), 365-380.

3. Green, S. R., Kirkham, M. B. and Clothier, B. E., Root uptake and transpiration: from measurements and models to sustainable irrigation. Agric. Water Manage., 2006, 86(1-2), 165-176.

4. Dardanelli, J. L., Ritchie, J. T., Calmon, M., Andriani, J. M. and Collino, D. J., An empirical model for root water uptake. Field Crops Res., 2004, 87(1), 59-71.

5. Prasad, R., A linear root water uptake model. J. Hydrol., 1988, 99, 297-306.

6. Govindraju, R. S., Or, D., Kavvas, M. L., Rolston, D. E. and Biggar, J., Error analyses of simplified unsaturated flow models under large uncertainty in hydraulic properties. Water Resour. Res., 1992, 28(11), 2913-2924.

7. Feddes, R. A., Kotwalik, P. J. and Zaradny, H., Simulation of field water use and crop yield. Centre for Agricultural Publishing and Documentation, Wageningen, The Netherlands, 1978.

8. Molz, F. J. and Remson, I., Extraction term models of soil moisture use by transpiring plants. Water. Resour. Res., 1970, 6(5), 1346-1356.

9. Ojha, C. S. P. and Rai, A. K., Non-linear root water uptake model J. Irrig. Drain. Eng., 1996, 122, 198-202.

10. Li, K. Y., Boisvert, J. B. and Jong, R. De, An exponential root water uptake model. Can. J. Soil. Sci., 1999, 79, 333-343.

11. Kang, S., Zhang, F. and Zhang, J., A simulation model of water dynamics in winter wheat field and its application in a semiarid region. Agric. Water. Manage., 2001, 49(2), 115-129.

12. Vrugt, J. A., Hopmans, J. W. and Simunek, J., Calibration of a two dimensional root water uptake model. Soil Sci. Soc. Am. J., 2001, 65, 1027-1037.

13. Jalota, S. K. and Arora, V. K., Model-based assessment of water balance components under different cropping systems in northwest India. Agric. Water. Manage., 2002, 57(1), 75-87.

14. Shankar, V., Modelling of Moisture Uptake by Plants, Ph D Dissertation, Department of Civil Engineering, IIT Roorkee, 2007.

15. Chakraborty, D., Nagarajan, S., Aggarwal, P., Gupta, V. K., Tomar, R. K., Garg, R. N. and Kalra, N., Effect of mulching on soil and plant water status, and the growth and yield of wheat (Triticumaestivum L.) in a semi-arid environment. Agric. Water. Manage., 2008, 95(12), 1323-1334.

16. Kumar, R., Jat, M. K. and Shankar, V., Evaluation of modeling of water ecohydrologic dynamics in soil-root system. Ecol. Model, $2013,269,51-60$

17. Kumar, R., Shankar, V. and Jat, M. K., Efficacy of nonlinear root water uptake model for a multilayer crop root zone. J. Irrig. Drain. Eng., 2013, 139(11), 898-910.

18. Kumar, R., Shankar, V. and Jat, M. K., Soil moisture dynamics modeling considering multi-layer root zone. Water. Sci. Technol., 2013, 67(8), 1778-1785.
19. Kumar, R., Shankar, V. and Jat, M., Evaluation of nonlinear root uptake model for uniform root zone vis-à-vis multilayer root zone. J. Irrig. Drain Eng., 2014, 140(2), 04013010; 10.1061/ (ASCE)IR.1943-4774.0000655.

20. Devatha, C. P., Shankar, V. and Ojha, C. S. P., Assessment of soil moisture uptake under different salinity levels for paddy crop. $J$. Irrig. Drain. Eng., 2016, 142(5), 04016011.

21. Poddar, A., Kumar, N. and Shankar, V., Evaluation of two irrigation scheduling methodologies for potato (Solanum tuberosum L.) in north-western mid-hills of India. ISH J. Hydraul. Eng., 2018, 1-10; https://doi.org/10.1080/09715010.2018.1518733

22. Ojha, C. S. P., Hari Prasad, K. S., Shankar, V. and Madramootoo, C. A., Evaluation of a nonlinear root water uptake model. J. Irrig. Drain. Eng. (ASCE), 2009, 35(3), 303-312.

23. Erie, L. J., French, O. F. and Harris, K., Consumptive use of water by crops in Arizona. Technical Bulletin, 169, Agricultural Experiment Station, University of Arizona, Tucson, Arizona, 1965.

24. Kumar, R., Shankar, V. and Jat, M. K., Evaluation of root water uptake models - a review. ISH J. Hydraul. Eng., 2015, 21(2), $115-124$.

25. Shankar, V., Hari Prasad, K. S., Ojha, C. S. P. and Rao Govindaraju, S., A model for nonlinear root water uptake parameter. J. Irrig. Drain. Eng. (ASCE), 2012, 138(10), 905-917; doi:50810.1061/(ASCE)IR.1943-4774.0000469.509.

26. Bandyopadhyay, P. K. and Mallick, S., Actual evapotranspiration and crop coefficients of wheat (Triticum aestivum) under varying moisture levels of humid tropical canal command area. Agric. Water. Manage., 2003, 59(1), 33-47.

27. Corbett, J. D., The changing face of agro-ecosystem characterization: Models and spatial data, the basis for robust agro-ecosystem characterization. Proceedings of the Third International Conference on the Integration of GIS and Environmental Modeling, Santa Fe, New Mexico, 1996.

28. Joshi, P. K., Maize in India: production systems, constraints, and research priorities. CIMMYT, 2005.

29. Richards, L. A., Capillary conduction of liquids through porous medium. Physics, 1931, 1, 318-333.

30. Celia, M. A., Bouloutas, E. T. and Zarba, R. L., A general mass conservative numerical solution for the unsaturated flow equation. Water. Resour. Res., 1990, 26, 1483-1496.

31. Van Genuchten MTh, A closed-form equation for predicting the hydraulic conductivity of unsaturated soils. Soil Sci. Soc. Am. J., 1982, 44, 892-898.

32. Shankar, V., Govindaraju, R. S., Ojha, C. S. P. and Hari Prasad, K. S., Non dimensional relationship for root water uptake in crops. J. Irrig. Drain. Eng., 2013, 139(11), 961-964.

33. Paniconi, C., Aldama, A. A. and Wood, E. F., Numerical evaluation of iterative and numerical methods for the solution of the nonlinear Richards equation. Water. Resour. Res., 1991, 27, 11471163.

34. Remson, I., Hornberger, G. M. and Molz, F. J., Numerical Methods in Subsurface Hydrology, Wiley-International, New York, 1971, p. 389.

35. Trout, T. J., Garcia-Castillas, I. G. and Hart, W. E., Soil Water Engineering: Field and Laboratory Manual, Academic Publishers, Jaipur, 1982.

36. Nandagiri, L. and Prasad, R., Relative performance of textural models in estimating soil moisture characteristic. J. Irrig. Drain. Eng. (ASCE), 1997, 123, 211-214.

37. Doorenbos, J. and Pruitt, W. O., Guidelines for predicting crop water requirements. Irrigation and Drain. Div, FAO-Rome, Paper No., 1977, p. 24.

38. Boehm, W., Ecological studies series, 33. Methods of Studying Root Systems (eds Billings, W. D. et al.), 1979, p. 188.

39. Allen, R. G., Pereira, L. S., Raes, D. and Smith, M., Crop evapotranspiration-guidelines for computing crop water 
requirements-FAO irrigation and drainage paper 56. Fao, Rome, 1998, 300(9), D05109.

40. Cai, J., Liu, Y., Lei, T. and Pereira, L. S., Estimating reference evapotranspiration with the FAO Penman-Monteith equation using daily weather forecast messages. Agric. Forest. Meteorol., 1966, 145(1-2), 22-35.

41. Kwon, H. and Choi, M., Error assessment of climate variables for FAO-56 reference evapotranspiration. Meteorol. Atmos. Phys., 2011, 112(1-2), 81-90.

42. Poddar, A., Gupta, P., Kumar, N., Shankar, V. and Ojha, C. S. P., Evaluation of reference evapotranspiration methods and sensitivity analysis of climatic parameters for sub-humid sub-tropical locations in western Himalayas (India). ISH J. Hydraul. Eng., 2018, 1-11; https://doi.org/10.1080/09715010.2018.1551731

43. Eberbach, P. and Pala, M., Crop row spacing and its influence on the partitioning of evapotranspiration by winter-grown wheat in Northern Syria. Plant. Soil, 2005, 268, 195-208.

44. Brown, K. W. and Covey, W., The energy-budget evaluation of the micrometeorological transfer processes within a corn field. Agric. Meteorol., 1966, 3, 73-96.

45. Denmead, O. T., Relative significance of soil and plant evaporation in estimating evapotranspiration. In Plant Response to Climatic Factors, Proceedings of Uppsala Symposium, UNESCO, Paris, 1973.

46. Raes, D., Van Aelst, P. and Wyseure, G., ETref, ETcrop, ETsplit and deficit, a computer package for calculating crop water requirements: reference manual. Laboratory of Soil and Water Engineering, Agricultural sciences, Leuven, Belgium, 1986.
47. Luo, Y. and Marios, S., Seasonal groundwater contribution to crop-water use assessed with lysimeter observations and model simulations. J. Hydrol., 2010, 389, 325-335.

48. Legates, D. R. and McCabe, G. J., Evaluating the use of 'goodness-of-fit' measures in hydrologic and hydro climatic model validation. Water Resour. Res., 1999, 35(1), 233-241.

49. Willmott, C. J. and Matsuura, K., Advantages of the mean absolute error (MAE) over the root mean square error (RMSE) in assessing average model performance. Climate Res., 2005, 30(1), 79-82.

ACKNOWLEDGEMENTS. We would like to acknowledge the Department of Civil Engineering, National Institute of Technology (NIT) Hamirpur for providing experimental facilities related to study. The climatic data for the study was provided by Centre for Energy and Environment Engineering, NIT Hamirpur. The financial support for the study was received through Ministry of Human Resource Development (MHRD), Ministry of Earth Sciences (Government of India) and Natural Environment Research Council (United Kingdom) sponsored project 'Sustaining Himalayan Water Resources in a changing climate (SusHi-Wat)'.

Received 21 November 2019; revised accepted 13 March 2020

doi: $10.18520 / \mathrm{cs} / \mathrm{v} 119 / \mathrm{i} 3 / 485-496$ 